\title{
Neue Strategien beim NSCLC: Was bringt die Hemmung der Tumorgefäße?
}

\author{
New Strategies for NSCLC: Is Inhibition of Tumour Vasculature Useful?
}

Autoren

Institute
N. Reinmuth ${ }^{1}$, M. Steins ${ }^{1}$, M. Kreuter ${ }^{2}$, M. Thomas ${ }^{1}$

Abteilung für Internistische Onkologie der Thoraxtumoren, Thoraxklinik am Universitätsklinikum Heidelberg, Heidelberg

Abteilung für Pneumologie und Beatmungsmedizin, Thoraxklinik am Universitätsklinikum Heidelberg, Heidelberg eingereicht 15.12 .2009

akzeptiert nach Revision 3.2. 2010

\section{Bibliografie}

DOI http://dx.doi.org/

10.1055/s-0029-1243974

Online-Publikation: 12. 3. 2010

Pneumologie 2010; 64 :

376-386 @ Georg Thieme

Verlag KG Stuttgart · New York

ISSN 0934-8387

\section{Korrespondenzadresse}

Dr. med. Niels Reinmuth

Internistische Onkologie der

Thoraxtumoren

Thoraxklinik am Universitäts-

klinikum Heidelberg

Amalienstr. 5

69126 Heidelberg

niels.reinmuth@thoraxklinik-

heidelberg.de

\section{Zusammenfassung \\ $\nabla$}

Lungenkarzinome sind die am häufigsten zum Tode führenden Tumorerkrankungen in Deutschland. Das verbesserte Verständnis der Tumorbiologie und der Bedeutung eines funktionellen Gefäßsystems für das Wachstum und die Metastasierung solider Tumoren resultierte in der Entwicklung neuer Substanzen, die vorwiegend das Gefäßsystem des Tumors zerstören sollen. Antiangiogene Substanzen hemmen die Neuentstehung von Gefäßen aus dem bereits existierenden Gefäßsystem und können die Gefäßstabilität beeinflussen. Mit Bevacizumab wurde bereits ein monoklonaler anti-VEGF-(vascular endothelial growth factor)-Antikörper zur Erstlinien-Behandlung des metastasierten oder fortgeschrittenen nicht kleinzelligen Lungenkarzinoms (NSCLC) ohne dominierende Plattenepithelhistologie in Kombination mit Platin-basierter Chemotherapie zugelassen. Klinische Studien zeigten vielversprechende Daten auch für die Kombination von klein-molekularen multi-Tyrosinkinase-Inhibitoren mit Zytostatika. Als differenter Therapieansatz wurden gefäßzerstörende Substanzen (Vascular Disrupting Agents, VDAs) entwickelt, die insbesondere etablierte Blutgefäße im Tumor zerstören sollen. In der vorliegenden Übersicht werden die Wirkprinzipien von anti-angiogenen Therapeutika und VDAs beschrieben und die aktuelle klinische Datenlage zusammengefasst.

\section{Einleitung}

Das Lungenkarzinom zählt zu den am häufigsten zum Tode führenden Karzinomen in Deutschland. Die klassischen Therapiemodalitäten umfassen die chirurgische Resektion, Chemotherapie und Strahlentherapie, die im Rahmen neoadjuvanter und adjuvanter Behandlungen oder auch für palliative Therapiestrategien kombiniert werden [1]. Da die Erkrankung zumeist erst im bereits metas-

\section{Abstract \\ $\nabla$}

Lung cancer is the leading cause of cancer-related mortality in Germany. Improvements in our understanding of cancer biology have led to the development of novel agents that inhibit the tumour vasculature in order to induce subsequent tumour cell death. In this context, the inhibition of tumour-related angiogenesis - the growth of new vessels from pre-existing vessels - has become an attractive target for anticancer therapy. Bevacizumab, a monoclonal antibody against vascular endothelial growth factor (VEGF), has already been approved in combination with platinum-based chemotherapy in patients with advanced nonsmall cell lung cancer (NSCLC) without predominant squamous cell histology. Moreover, small molecule inhibitors targeting multiple angiogenic receptors have also shown promise when combined with standard chemotherapy. As a different approach, vascular disrupting agents (VDAs) have been designed to particularly target preexisting blood vessels which may lead to a vascular shut-down. In the present review, both principles of action and current clinical data on anti-angiogenic agents and VDAs in the treatment of patients with NSCLC are reviewed. tasierten Stadium diagnostiziert wird [2], bleibt die allgemeine Prognose für das Lungenkarzinom schlecht: Die 5-Jahres-Überlebenszeit liegt beim nicht kleinzelligen Lungenkarzinom (NSCLC) durchschnittlich bei 8-14\% [3], beim kleinzelligen Lungenkarzinom sogar nur bei $4 \%$ [4]. Seit mehreren Jahren wird daher intensiv nach neuen Therapieansätzen für das Lungenkarzinom gesucht. Hierbei lag der Fokus über eine lange Zeit ausschließlich auf Hemmung und Zerstörung der 
Tumorzellen selbst. Da diese durch verschiedene zelluläre und funktionelle Veränderungen charakterisiert sind, wird versucht, essenzielle Signalmechanismen mit möglichst hoher Selektivität für Tumorzellen zu identifizieren und spezifische Therapiestrategien zu entwickeln [5].

Eine andere Forschungsrichtung versucht, Tumorzellen durch Reduktion der Durchblutung „auszuhungern“ [6]. Alle Körperzellen müssen ausreichend mit Sauerstoff und Nährstoffen versorgt werden, um überleben und wachsen zu können. Somit sind auch Tumorzellen, die weiter entfernt als die Diffusionsgrenze für Sauerstoff (ca. 100 - $200 \mu \mathrm{m}$ ) liegen, auf die Bildung neuer Blutgefäße angewiesen. Zudem benötigen Tumoren einen Anschluss an das Blutgefäßsystem, um hämatogene Metastasen bilden zu können. In präklinischen und klinischen Studien zeigte sich, dass ein Tumor mehrere Möglichkeiten zur Akquirierung eines Gefäßsystems hat.

Die eigentliche Angiogenese („Gefäßerschaffung“) beschreibt den Vorgang der Neubildung von Blutgefäßen aus einem bereits bestehenden Kapillarsystem [7,8]. Die Aktivierung spezifischer Endothelzell-Rezeptoren durch angiogene Faktoren führt zur Proliferation, Invasion der Basalmembran, Migration und Differenzierung von Endothelzellen, die schließlich neue Kapillargefäße bilden. Nachfolgend kommt es zu zahlreichen Umbauvorgängen der neuen Endothelzellstränge in ein reiferes Gefäßsystem mit Ummantelung durch perivaskuläre Zellen, welches durch eine höhere Stabilität charakterisiert ist [7,9]. Neben dieser „sprießenden“ Angiogenese ist auch eine „nicht sprießende“ Angiogenese beobachtet worden mit Vergrößerung, Teilung und Fusion prä-existierender Gefäße durch Proliferation von Endothelzellen innerhalb der Gefäßwand [10]. Zudem konnte in experimentellen Tumormodellen das Vorkommen von Vaskulogenese gezeigt werden, die Formierung neuer Blutgefäße durch zirkulierende endotheliale Progenitorzellen aus dem Knochenmark (Angioblasten). Diese konnten auch in Tumorgeweben und im peripheren Blut von Tumorpatienten detektiert werden, allerdings nur in sehr geringen Konzentrationen [11,12]. Daher bleibt die Bedeutung der Vaskulogenese bei der Gefäßversorgung des adulten Tumors umstritten [12]. Eine weitere Quelle von Tumorgefäßen ist die Adaption des bereits präexistierenden Gefäßsystems des jeweiligen Organs [10,13]. Besonders der letztgenannte Mechanismus könnte für Lungentumoren bedeutsam sein, da die Lunge über ein dichtes Gefäßnetz verfügt, welches aus der Pulmonalarterie und - besonders relevant für Lungentumoren aus der Aorta über Bronchialarterien versorgt wird. Allerdings ist die tatsächliche Bedeutung der Adaption dieses Gefäßsystems für Lungenkarzinome unklar. Bei immunhistochemischen Analysen an Gewebepräparaten von 56 NSCLC Patienten im Stadium I und II zeigten 45 Tumoren (80\%) zumindest anteilig ein Gefäßmuster, welches durch seine charakteristische Architektur und ausgeprägte Ummantelung mit perivaskulären Zellen wie Perizyten und glatten Gefäßmuskelzellen als adaptiertes präexistierendes Gefäßsystem angesehen werden konnte [14].

Perizyten sind durch ihre Lage innerhalb der Basalmembran von Kapillaren und postkapillären Venolen charakterisiert und bei der Regulation zahlreicher Gefäßfunktionen beteiligt $[15,16]$. Dagegen sind glatte Gefäßmuskelzellen in größeren Gefäßen anzutreffen, die sie meist in mehreren Schichten zusammen mit elastischen und kollagenen Fasern umhüllen. Die Ummantelung kleiner Gefäße mit Perizyten und Gefäßmuskelzellen gilt als Zeichen höherer Gefäßreife und -stabilität $[9,17]$. Tumorgefäße unterscheiden sich von normalen Organgefäßen durch eine allgemein geringere Anzahl assoziierter perivaskulärer Zellen und weiteren strukturellen Zeichen der Gefäßunreife wie wechselnder Gefäßdurchmesser, Mikroaneurysmen, hohe Gefäßdurchlässigkeit $[18,19]$. Daher werden Tumorgefäße, insbesondere neu gebildete Gefäße, als weniger stabil angesehen als normale Organgefäße [7,20]. Der differente strukturelle Aufbau von Tumorgefäßen erklärt auch die höhere Anfälligkeit dieser Gefäße gegenüber anti-angiogenen und anti-endothelialen Substanzen in klinischen Studien im Vergleich zu normalen Organgefäßen [21]. Unklar ist jedoch, ob die oben skizzierten Entstehungsformen von Tumorgefäßen (Angiogenese, Vaskulogenese, Gefäß-Adaption) zu verschiedenen Gefäßen führen, die möglicherweise unterschiedlich auf eine spezifische Therapie ansprechen. Dies würde zu einem heterogenen Ansprechen von Gefäßen innerhalb eines Tumors führen.

\section{Anti-Angiogenese}

Die Angiogenese ist ein sehr komplexer Prozess, der durch multiple pro- und anti-angiogene Faktoren reguliert wird, die von Tumorzellen, stromalen und inflammatorischen Zellen sezerniert oder durch Proteasen aus der extrazellulären Matrix freigesetzt werden [22]. Verschiebt sich das Verhältnis zu Gunsten angiogener Faktoren, wird die Neubildung von Gefäßen initiiert, welches allgemein als Erhöhung des malignen Potenzials eines Tumor interpretiert wird [23]. Daher ist das Ziel einer anti-angiogenen Strategie entweder die Hemmung ein oder mehrerer pro-angiogener Faktoren oder direkt die Zugabe von natürlich vorkommenden anti-angiogenen Molekülen (z. B. Angiostatin). Als einer der Schlüsselfaktoren für Angiogenese gilt der vaskuläre endotheliale Wachstumsfaktor (VEGF; ausführliche Übersichtsarbeiten in $[8,24])$. VEGF wird insbesondere bei Hypoxie und durch verschiedene epitheliale Wachstumsfaktoren vermehrt gebildet und induziert Proliferation, Invasion und Migration von Endothelzellen, was zur Bildung neuer Gefäße führt. Zudem wird die mikrovaskuläre Permeabilität erhöht. Schließlich schützt VEGF neue Endothelzellstränge vor Apoptose und vermittelt dadurch eine erhöhte Gefäßstabilität besonders bei den Gefäßen, die noch nicht durch perivaskuläre Zellen ummantelt sind [9]. Die Erforschung von VEGF als ein zentraler angiogener Faktor führte zur Entwicklung verschiedener anti-VEGF Substanzen einschließlich kleinmolekularer Rezeptortyrosinkinase-Inhibitoren und Antikörper ( Tab. 1) [25]. Bei einer alleinigen Hemmung von VEGF sollte bei hoher Abhängigkeit der Angiogenese von diesem Faktor die Gefäßneubildung unterbunden sein. Der klinisch zu erwartende Effekt entspräche daher einer Stabilisierung der Erkrankung. Tatsächlich zeigte sich in einer klinischen Phase I Studie bei verschiedenen Tumoren bei einer anti-VEGF Antikörper-Monotherapie keine Tumorreduktion, aber eine Krankheitsstabilität bei 12/23 Patienten über die Dauer der Studie [26]. Dagegen wurden bei einer Kombinationstherapie mit zytotoxischen Substanzen deutliche Tumorremissionen beschrieben $[27,28]$. Als Erklärung sind verschiedene Hypothesen formuliert worden einschließlich Gefäßnormalisierung durch die anti-angiogene Therapie mit verbesserter Applikation der Chemotherapeutika [29] und Inhibition von Chemotherapie-Resistenzmechanismen durch die anti-VEGF -Therapie [30,31].

Im Gegensatz zur initialen Annahme [6] wurden jedoch auch Resistenzmechanismen gegenüber anti-angiogenen Substanzen beschrieben: Eine längere Behandlung von murinen neuroendokrinen Pankreastumoren und Glioblastomen mit anti-VEGFR2-Antikörpern führte nach initialer deutlicher Tumorreduktion zur 
Tab. 1 Anti-angiogene Substanzen (nach [25]).

\begin{tabular}{|c|c|c|}
\hline \multirow[t]{6}{*}{ VEGF-blockierende Substanzen } & Bevacizumab (Avastin ${ }^{\circledR}$ ) & Humanisierter anti-VEGF-A monoklonaler Antikörper \\
\hline & Ranibizumab (Lucentis ${ }^{\circledR}$ ) & Anti-VEGF-A Antikörper F(ab) Fragment \\
\hline & Pegaptanib (Macugen ${ }^{\circledR}$ ) & RNA Aptamer der 165-Aminosäuren VEGF-A \\
\hline & IMC-1121B & Humaner anti-VEGFR-2 monoklonaler Antikörper \\
\hline & DC101 & Muriner VEGFR-2-spezifischer monoklonaler Antikörper \\
\hline & Aflibercept (VEGF-Trap) & $\begin{array}{l}\text { Fusionsprotein der Immunoglobulin Domänen von VEGFR und } \\
\text { VEGFR-2 und human IgG1 FC Fragment }\end{array}$ \\
\hline \multirow[t]{15}{*}{ Multi-Tyrosinkinase-Inhibitoren } & AEE788 & VEGFR-2- und EGFR-Inhibitor \\
\hline & Axitinib (AG-013736) & VEGFR-selektiver Inhibitor \\
\hline & AG-013925 & VEGFR- und PDGFR-Inhibitor \\
\hline & Imatinib & Inhibitor von Bcr-Abl Fusionsprotein und PDGFR- $\beta$, c-KIT \\
\hline & Vatalanib (PTK787/ZK22258) & VEGFR-2-Inhibitor, auch Aktivität gegen VEGFR-1, VEGFR-3 PDGFR- $\beta$ \\
\hline & BIBF1120 $\left(\operatorname{Vargatef}^{\circledR}\right)$ & Inhibitor von VEGFR $1-3$, PDGFR- $\alpha$ und $-\beta$ und FGFR $1-3$ \\
\hline & Sorafenib (BAY $43-9006$, Nexavar ${ }^{\circledR}$ ) & $\begin{array}{l}\text { Inhibiert Raf, VEGFR-2, VEGFR-3, auch Aktivität gegen PDGFR- } \beta \text {, } \\
\text { FIt-3, c-KIT }\end{array}$ \\
\hline & Semaxanib (SU5416) & VEGFR-2-Inhibitor, auch Aktivität gegen PDGFR \\
\hline & SU6668 & VEGFR-2-Inhibitor, auch Aktivität gegen PDGFR- $\beta$, FGFR -1, and c-KIT \\
\hline & SU11657 & $\begin{array}{l}\text { VEGFR-1- und VEGFR-2-Inhibitor, auch Aktivität gegen PDGFR- } \alpha \text {, } \\
\text { PDGFR- } \beta, c-K I T\end{array}$ \\
\hline & Sunitinib (SU11248, Sutent $\left.{ }^{\circledR}\right)$ & $\begin{array}{l}\text { VEGFR-1- und VEGFR-2-Inhibitor, auch Aktivität gegen PDGFR- } \alpha \text {, } \\
\text { PDGFR- } \beta, \text {, c-KIT }\end{array}$ \\
\hline & Vandetanib (ZD6474, Zactima ${ }^{\circledR}$ ) & VEGFR-2-Inhibitor, auch Aktivität gegen VEGFR-3 und EGFR \\
\hline & Cediranib (ZD2171) & $\begin{array}{l}\text { VEGFR-2-Inhibitor, auch Aktivität gegen VEGFR-1, VEGFR-3, c-KIT, } \\
\text { PDGFR- } \beta\end{array}$ \\
\hline & Motesanib (AMG-706) & Inhibitor von VEGFR1 - 3, PDGFR und c-kit \\
\hline & AE-941 (Neovastat $\left.{ }^{\circledR}\right)$ & Inhibiert VEGFR2 und MMP-2, -9 und -12 \\
\hline \multirow[t]{3}{*}{ Endogene Inhibitoren } & Angiostatin & Spalt-Fragment von Plasminogen \\
\hline & Endostatin & Spalt-Fragment von Collagen XVIII \\
\hline & Thrombospondin-1 & Extrazelluläres Glykoprotein \\
\hline
\end{tabular}

Abkürzungen: EGFR (epidermal growth factor receptor), FGFR (fibroblast growth factor receptor), MMP (Matrix Metalloproteinase), PDGF (platelet-derived growth factor receptor), VEGF (vascular endothelial growth factor receptor).
Ausbildung einer Therapieresistenz gegen VEGFR2-Hemmung mit erneutem Tumorwachstum und VEGF-unabhängiger Reaktivierung von Angiogenese durch Induktion alternativer angiogener Faktoren wie FGF $[23,32]$. Die Beteiligung mehrerer angiogener Faktoren bei der Tumorangiogenese wurde auch bei immunhistochemischen Expressionsanalysen von Tumorpräparaten von NSCLC-Patienten nachgewiesen, bei denen eine Expression von FGF2 als unabhängiger negativer prognostischer Faktor identifiziert wurde [33].

\section{Bevacizumab}

Bevacizumab ist ein humanisierter monoklonaler anti-VEGF Antikörper mit guter klinischer Aktivität in Kombination mit Chemotherapie bei verschiedenen Tumoren [25]. Aufgrund der Daten zweier Phase-III-Studien ist Bevacizumab in Kombination mit platinbasierter Chemotherapie zur Erstlinien-Behandlung des metastasierten oder fortgeschrittenen NSCLC ohne dominierende Plattenepithelhistologie zugelassen. In der ECOG4599-Studie wurde durch die Addition von $15 \mathrm{mg} / \mathrm{kg}$ Bevacizumab zu einer Therapie mit Carboplatin AUC 6 und $200 \mathrm{mg} / \mathrm{m}^{2}$ Paclitaxel bei Stadium IIIB/IV NSCLC eine signifikante Verbesserung des Therapieansprechens (von 15\% auf 35\%, p <0,001), des medianen progressionsfreien Überlebens (PFS; von 4,5 auf 6,2 Monate, $\mathrm{p}<0,0001$ ) und des medianen Gesamtüberlebens (von 10,3 auf 12,3 Monate, $\mathrm{p}=0,003$ ) gezeigt [28]. Patienten mit dominierender Plattenepithel-Histologie waren aufgrund erhöhter Blutungskomplikationen einer früheren Phase-II-Studie ausgeschlossen [34]. Diese Ergebnisse wurde teilweise durch eine wei- tere Phase-III-Studie (AVAiL) bestätigt, in der Stadium III/IV NSCLC-Patienten mit einer Kombination aus $80 \mathrm{mg} / \mathrm{m}^{2}$ Cisplatin und $1250 \mathrm{mg} / \mathrm{m}^{2}$ Gemzitabine behandelt wurden und bei Addition von Bevacizumab in zwei unterschiedlichen Dosierungen jeweils eine signifikante Verlängerung des PFS zeigten (niedrige Dosierung $7,5 \mathrm{mg} / \mathrm{kg}, \mathrm{p}=0,003$. Hohe Dosierung $15 \mathrm{mg} / \mathrm{kg}$, $\mathrm{p}=0,03$ ) [27]. Der Netto-Gewinn lag jedoch im Median bei nur 0,6 Monaten (für den Niedrig-Dosisarm) und 0,4 Monaten (für den Hoch-Dosisarm). Der geringe Unterschied wurde teilweise durch ein eher prognostisch günstigeres Patientenkollektiv erklärt. Im Kontrollarm behandelte Patienten zeigten ein medianes PFS von 6,1 Monaten in der AVAiL-Studie im Vergleich von 4,5 Monaten in der ECOG4599-Studie.

Die Addition von Bevacizumab zur Chemotherapie resultierte auch in vermehrten Nebenwirkungen. In der ECOG4599-Studie wurden signifikant höhere Grad-4-Toxizitäten bezüglich Neutropenie $(25,5 \%$ versus $16,8 \%, \mathrm{p}=0,002)$, Thrombozytopenie $(1,6 \%$ versus $0,2 \%, p=0,04)$ und febriler Neutropenie $(5,2 \%$ versus $2 \%$, $\mathrm{p}=0,02)$ gefunden [28]. Zudem wurden Nebenwirkungen wie Grad 3-4-Hypertonie (7,7\% versus 0,7\%, p < 0,001), Hämorrhagie $(4,4 \%$ versus $0,7 \%, p<0,001)$ und Proteinurie $(3,1 \%$ versus $0 \%$, $\mathrm{p}<0,001$ ) beobachtet. Eine hypertone Entgleisung oder eine Proteinurie war allgemein klinisch gut beherrschbar. Aufgrund seltener letaler Hämorrhagien (in der ECOG4599-Studie: 5 pulmonal, 1 zerebralvaskulär, 1 gastrointestinal) wird der Einsatz bei Patienten mit Hämoptysen $>1$ Teelöffel, bronchoskopisch suspekt erscheinenden zentralen Tumoren und Plattenepithelkarzinomen derzeit nicht empfohlen. Nach retrospektiven Analysen bisheriger Studiendaten und einer kürzlich publizierten Phase-IIStudie hat die Europäische Arzeimittelagentur (EMEA) für Beva- 
Tab. 2 Klinische Ergebnisse mit multi-Tyrosinkinase-Inhibitoren (aus [43]).

\begin{tabular}{|c|c|c|c|c|c|c|c|}
\hline Therapie & Phase & $\mathrm{PI}-\mathrm{Ca}$ & Linie & $\mathbf{N}$ & $\mathrm{RR}(\%)$ & OS (Monate) & Literatur \\
\hline $\begin{array}{l}\text { Carboplatin AUC } 6 \text { + Paclitaxel } 225 \mathrm{mg} / \mathrm{m}^{2} \\
\text { Tag } 1 \text { alle } 3 \text { Wochen } \\
\text { Carboplatin AUC } 6 \text { + Paclitaxel } 225 \mathrm{mg} / \mathrm{m}^{2} \\
\text { Tag } 1 \text { + Sorafenib } 400 \mathrm{mg} \text { zweimal/Tag }\end{array}$ & III & $x$ & 1 & $\begin{array}{l}462 \\
464\end{array}$ & $\begin{array}{l}24 \\
30\end{array}$ & $\begin{array}{l}10,7 \\
10,6\end{array}$ & [42] \\
\hline $\begin{array}{l}\text { Cisplatin } 80 \mathrm{mg} / \mathrm{m} 2 \text { Tag } 1+\text { Gemzitabine } \\
1000 \text { or } 1250 \mathrm{mg} / \mathrm{m}^{2} \text { Tage } 1 \text { und } 8 \text { alle } 3 \text { Wochen } \\
\text { + Sunitinib } 37.5 \text { oder } 50 \mathrm{mg} / \text { Tag }\end{array}$ & 1 & $x$ & 1 & 13 & 23 & NA & [47] \\
\hline $\begin{array}{l}\text { Carboplatin AUC } 6 \text { + Paclitaxel } 200 \mathrm{mg} / \mathrm{m}^{2} \\
\text { Tag } 1 \text { alle } 3 \text { Wochen + Cediranib } 30 \text { or } 45 \mathrm{mg} / \text { Tag }\end{array}$ & 1 & $x$ & 1 & 20 & 45 & NA & [84] \\
\hline $\begin{array}{l}\text { Carboplatin AUC } 6 \text { + Paclitaxel } 225 \mathrm{mg} / \mathrm{m}^{2} \\
\text { Tag } 1 \text { alle } 3 \text { Wochen } \\
\text { Carboplatin AUC } 6 \text { + Paclitaxel } 225 \mathrm{mg} / \mathrm{m}^{2} \\
\text { Tag } 1 \text { alle } 3 \text { Wochen+ Vandetanib } 300 \mathrm{mg} / \text { Tag } \\
\text { Vandetanib } 300 \mathrm{mg} / \text { Tag }\end{array}$ & II & $\mathrm{x}$ & 1 & $\begin{array}{l}52 \\
56 \\
73\end{array}$ & $\begin{array}{r}25 \\
32 \\
7\end{array}$ & NA & [85] \\
\hline $\begin{array}{l}\text { XL647 } 350 \mathrm{mg} / \text { Tage } 1 \text { - 5, XL647 } 300 \mathrm{mg} / \text { Tag } \\
\text { Tage 6-13 }\end{array}$ & II & Nein & 1 & 41 & 28 & NA & [86] \\
\hline Axitinib 5 mg zweimal/Tag & II & $x$ & $\geq 1$ & 32 & 9 & 14,8 & [87] \\
\hline $\begin{array}{l}\text { Carboplatin AUC } 6 \text { + Paclitaxel } 225 \mathrm{mg} / \mathrm{m}^{2} \text { day } \\
1 \text { + Sorafenib } 400 \mathrm{mg} \text { zweimal/Tag an } \\
\text { Tagen } 2-18 \text { alle } 3 \text { Wochen }\end{array}$ & $I-I I$ & $x$ & $>1$ & 15 & 29 & NA & [88] \\
\hline $\begin{array}{l}\text { Pemetrexed } 500 \mathrm{mg} / \mathrm{m}^{2}+\text { BIBF } 1120 \\
100-200 \mathrm{mg} \text { zweimal/Tag }\end{array}$ & I & $\mathrm{x}$ & $>1$ & 26 & 15 & NA & [62] \\
\hline Sunitinib $50 \mathrm{mg} / \mathrm{Tag}$ & II & $x$ & $>1$ & 63 & 11 & 5,4 & [45] \\
\hline AE-941 30, 60, 120 , or $240 \mathrm{ml} /$ Tag 80 & 1 & $x$ & $>1$ & 80 & 0 & $\begin{array}{l}\leq 2.6 \mathrm{ml} / \mathrm{kg} / \text { Tag: } 4.6 \\
>2.6 \mathrm{ml} / \mathrm{kg} / \text { Tag: } 6.1\end{array}$ & [89] \\
\hline $\begin{array}{l}\text { Docetaxel } 75 \mathrm{mg} / \mathrm{m}^{2} \text { alle } 3 \text { Wochen } \\
\text { Docetaxel } 75 \mathrm{mg} / \mathrm{m}^{2} \text { alle } 3 \text { Wochen + Vandetanib } \\
100 \mathrm{mg} / \mathrm{Tag} \\
\text { Docetaxel } 75 \mathrm{mg} / \mathrm{m}^{2} \text { alle } 3 \text { Wochen + Vandetanib } \\
300 \mathrm{mg} / \mathrm{Tag}\end{array}$ & II & $\mathrm{x}$ & 2 & $\begin{array}{l}41 \\
44 \\
42\end{array}$ & $\begin{array}{l}12 \\
26 \\
18\end{array}$ & $\begin{array}{r}13,4 \\
13,1 \\
7,9\end{array}$ & [53] \\
\hline $\begin{array}{l}\text { Vandentanib } 300 \mathrm{mg} / \mathrm{Tag} \\
\text { Erlotinib } 150 \mathrm{mg} / \mathrm{Tag}\end{array}$ & III & $x$ & 2 & $\begin{array}{l}623 \\
617\end{array}$ & $\begin{array}{l}12 \\
12\end{array}$ & $\begin{array}{l}6,9 \\
7,8\end{array}$ & [57] \\
\hline $\begin{array}{l}\text { Vandetanib } 100 \mathrm{mg} / \mathrm{Tag} \text { + Pemetrexed } 500 \mathrm{mg} / \mathrm{m}^{2} \\
\text { Pemetrexed } 500 \mathrm{mg} / \mathrm{m}^{2}\end{array}$ & III & $x$ & 2 & $\begin{array}{l}256 \\
278\end{array}$ & $\begin{array}{l}19,1 \\
7,9\end{array}$ & $\begin{array}{r}10,5 \\
9,2\end{array}$ & [56] \\
\hline $\begin{array}{l}\text { Vandetanib } 100 \mathrm{mg} / \mathrm{Tag} \text { + Docetaxel } 75 \mathrm{mg} / \mathrm{m}^{2} \\
\text { Docetaxel } 75 \mathrm{mg} / \mathrm{m}^{2}\end{array}$ & III & $x$ & 2 & $\begin{array}{l}694 \\
697\end{array}$ & $\begin{array}{l}17 \\
10\end{array}$ & $\begin{array}{l}10,6 \\
10,0\end{array}$ & [55] \\
\hline $\begin{array}{l}\text { Vandetanib } 100 \mathrm{mg} / \mathrm{Tag} \\
\text { Vandetanib } 200 \mathrm{mg} / \mathrm{Tag} \\
\text { Vandetanib } 300 \mathrm{mg} / \mathrm{Tag}\end{array}$ & II & $\mathrm{x}$ & 2 & $\begin{array}{l}17 \\
18 \\
18\end{array}$ & $\begin{array}{r}17 \\
6 \\
17\end{array}$ & NA & [51] \\
\hline $\begin{array}{l}\text { Sorafenib } 400 \mathrm{mg} \text { zweimal/Tag } \\
\text { Placebo }\end{array}$ & II & $\mathrm{x}$ & $>2$ & $\begin{array}{l}51 \\
32\end{array}$ & $\begin{array}{l}2 \\
3\end{array}$ & $\begin{array}{r}11,9 \\
9,0\end{array}$ & [41] \\
\hline BIBF 1120150 oder 250 mg zweimal/Tag & II & $x$ & $2 / 3$ & 73 & 0 & $\begin{array}{l}9,5 \\
(\text { ECOG } 0-1)\end{array}$ & [60] \\
\hline Sunitinib $37.5 \mathrm{mg} / \mathrm{Tag}$ & II & $x$ & $2 / 3$ & 47 & 2 & 8,6 & [46] \\
\hline XL647 300 mg/Tag & II & $\mathrm{x}$ & 3 & 23 & 4 & NA & [90] \\
\hline
\end{tabular}

Abkürzungen: AUC, area under the curve; NA, nicht angegeben. PI-Ca: Plattenepithelkarzinome eingeschlossen.

cizumab die bisherige Kontraindikation „unbehandelte ZNS-Metastasen" aufgehoben [35,36].

Eine retrospektive Subgruppenanalyse der ECOG4599-Studie von über 70-jährigen Patienten (bei 224 von insgesamt 878 Patienten) zeigte eine vermehrte Toxizität bei Bevacizumab-haltiger Kombinationstherapie (Grad 3-5-Toxizitäten bei $87 \%$ versus $61 \%$ für Patienten mit alleiniger Chemotherapie) [37]. Das mediane Gesamtüberleben der beiden Therapiegruppen war in dieser Subgruppe nicht signifikant verschieden (11,3 versus 12,1 Monate, $\mathrm{p}=0,4$ ) bei einem Trend $z u$ verbessertem medianen PFS für Patienten im Bevacizumab Arm (5,9 versus 4,9 Monate, $\mathrm{p}=0,063$ ). Dagegen war in der AVAiL-Studie bei über 65-jährigen Patienten (304 von insgesamt 1043 Patienten) das PFS im Niedrigdosis-Bevacizumab-Arm $(7,5 \mathrm{mg} / \mathrm{kg})$ im Vergleich zum Placebo-Arm signifikant verlängert bei ähnlicher Verträglichkeit wie das Gesamtkollektiv [38].
Aktuell werden für Bevacizumab verschiedene Konzepte wie Kombination zu adjuvanten Therapien oder Kombinationen mit Radiotherapie oder EGFR-Inhibitoren bei fortgeschrittenen Tumorstadien klinisch evaluiert.

\section{Multi-Tyrosinkinase-Inhibitoren}

In präklinischen Studien konnte überzeugend gezeigt werden, dass eine Mono-anti-VEGF-Therapie von Tumoren zur Induktion alternativer angiogener Faktoren wie bFGF (basic fibroblast growth factor) als Resistenzmechanismus führen kann [32]. Zudem sind bei der Mehrzahl der Tumoren mehrere angiogene Faktoren bei der komplizierten Regulation der Gefäßneubildung und -stabilität beteiligt. Beispielsweise konnte präklinisch und in Tumorbiopsien die Präsenz von bFGF, PDGF (platelet derived 
growth factor), MMPs (matrix metalloproteinases), HGF (hepatocyte growth factor), Angiopoietine und weiterer Faktoren gezeigt werden $[14,20,22]$. Insbesondere PDGF scheint eine große Bedeutung für die Ausbildung einer Gefäßstabilität durch Rekrutierung von Perizyten und glatten Muskelzellen zu besitzen, wodurch eine erhöhte Resistenz gegenüber apoptotischen Stimuli generiert wird $[9,17]$. Durch die gleichzeitige Hemmung mehrerer Schlüsselrezeptoren wird daher eine verbesserte anti-angiogene Wirkung und Verhinderung von Escape-Mechanismen erwartet [39]. Es gibt eine Reihe anti-angiogener Substanzen mit breiterem Wirkmuster, meist kleinmolekulare multi-Tyrosinkinase-Inhibitoren (multi-TKIs), die sich in Stadien klinischer Testung befinden ( Tab.2). Auf einige Substanzen mit bereits größerer klinischer Erfahrung soll im Folgenden kurz eingegangen werden.

\section{Sorafenib \\ $\nabla$}

Dies ist ein oraler multi-TKI, der die Rezeptoren VEGFR-2 und -3, PDGFR- $\beta$, RAF, c-Kit (stem cell factor receptor) und Flt-3 (fms-like tyrosine kinase-3) hemmt [40]. In einer klinischen Phase-II-Studie wurden 107 Patienten mit progredientem NSCLC und nach mindestens zwei vorausgegangenen Therapieschemata mit Sorafenib oder Placebo behandelt. In einer vorläufigen Auswertung von 83 Patienten hatten Sorafenib behandelte Patienten eine bessere Krankheitskontrolle ( 16 versus 2 Patienten, $p=0,002$ ) und ein besseres medianes PFS (3,6 versus 1,9 Monate, $p=0,009$ ) [41]. Als wichtigste Nebenwirkungen wurden Rash, Hand-Fuß-Syndrom, gastrointestinale Symptome und höhere Inzidenzen für Infektionen und Fatigue berichtet. Eine Phase-III-Studie (ESCAPE) mit 926 Stadium IIIB/IV NSCLC-Patienten, in der eine Kombination aus Carboplatin und Paclitaxel mit oder ohne $400 \mathrm{mg}$ Sorafenib als Erstlinientherapie getestet wurde, musste allerdings nach einer geplanten Zwischenauswertung abgebrochen werden, da zwischen den beiden Therapiearmen kein signifikanter Unterschied bezüglich Ansprechen, PFS ( $p=0,51)$ oder Gesamtüberleben $(p=0,93)$ gefunden wurde und der primäre Endpunkt (Verlängerung des Gesamtüberlebens) absehbar nicht mehr erreicht werden konnte. Zudem zeigten Patienten mit Plattenepithelkarzinomen ein signifikant schlechteres medianes Gesamtüberleben im Sorafenib-Arm (8,9 Monate versus 13,6 Monate; $\mathrm{p}<0,05$ ) $[42,43]$. Daher werden in einer aktuellen multizentrischen Studie (MISSION), bei der eine Sorafenib-Monotherapie beim schwer vorbehandelten fortgeschrittenen NSCLC (mindestens 2 vorherige Therapien) untersucht werden soll, Patienten mit Plattenepithelkarzinomen ausgeschlossen. Ergebnisse weiterer Phase-III-Studien einschließlich einer Kombination mit Cisplatin und Gemzitabine stehen aus.

\section{Sunitinib}

Sunitinib ist ein weiterer kleinmolekularer multi-TKI mit präklinischer Effektivität gegen die Rezeptoren VEGFR1 - 3, PDGFR- $\alpha$ und - $\beta$, FLT3, c-kit und RET [44]. Zwei Phase-II-Studien mit Sunitinib Monotherapie ( $50 \mathrm{mg} / \mathrm{d}$ für 4 Wochen gefolgt von 2 Wochen Pause) als Zweit- oder Drittlinientherapie bei 63 und 47 NSCLCPatienten zeigten ein medianes PFS von 12 und 12,3 Wochen und ein medianes Gesamtüberleben von 23,4 und 37,1 Wochen $[45,46]$. Auffälligste Nebenwirkungen waren Fatigue, Myalgien, Übelkeit und Erbrechen, Dyspnoe, kongestive Herzinsuffizienz und Mukositis. In der ersten Studie wurden 2/3 Hämorrhagien mit letalem Ausgang im Sunitinib-Arm beobachtet [45]. Auch als Erstlinientherapie in Kombination mit Cisplatin und Gemzitabine wurde Sunitinib in verschiedener Dosierung $(37,5 \mathrm{mg} / \mathrm{d}$ und $50 \mathrm{mg} / \mathrm{d}$ ) untersucht [47]. Als Grad 3/4-Toxizitäten wurden Neutropenie, Anämie und Thrombozytopenie vorwiegend im höheren Sunitinib-Dosis-Arm berichtet. Aktuell rekrutiert eine Phase-III-Studie nicht progrediente NSCLC-Patienten im Stadium IIIB/IV nach 4 Zyklen platinhaltiger Chemotherapie für eine Erhaltungstherapie mit Sunitinib oder Placebo (CALGB 30607). Eine weitere Phase-III-Studie, die eine Zweitlinientherapie mit Erlotinib in Kombination mit Sunitinib oder Placebo bei NSCLCPatienten evaluiert, hat mittlerweile ihre Rekrutierung abgeschlossen (SUN 1087). Erste Ergebnisse werden für 2010 erwartet.

\section{Vandetanib}

Vandetanib ist ein oraler multi-TKI mit dominierender Aktivität gegen VEGFR-2, VEGFR-3 und RET (RET, rearranged during transfection) sowie moderater Hemmung des EGFR (epidermal growth factor receptor) $[48,49]$. Der Beitrag der Inhibition der RET-Kinase zur anti-NSCLC-Aktivität ist im Gegensatz zu Schilddrüsenkarzinomen allerdings unklar [50]. In präklinischen Studien wurde eine Wirkung bei multiplen Tumormodellen einschließlich NSCLC beobachtet [49]. In einer randomisierten Dosis-Findungsstudie konnte eine gute Verträglichkeit von 100 $300 \mathrm{mg} / \mathrm{d}$ Vandetanib per os gezeigt werden mit Hautausschlag, Diarrhö, Hypertonie und asymptomatischer QTc-Verlängerung als häufigste Nebenwirkungen [51]

Drei Phase-II-Studien untersuchten die Effektivität von Vandetanib beim NSCLC: Bei 168 vorbehandelten NSCLC-Patienten im Stadium IIIB/IV hatten Patienten, die mit 300 mg/d Vandetanib therapiert wurden, ein erhöhtes Ansprechen ( $8 \%$ versus $1 \%$ ) und ein verlängertes PFS (11,9 versus 8,1 Wochen, $\mathrm{p}=0,011)$ im Vergleich zu $250 \mathrm{mg} / \mathrm{d}$ Gefitinib-behandelten Patienten [52]. In einer weiteren Studie wurde eine Zweitlinientherapie bei NSCLC mit Docetaxel allein oder in Kombination mit unterschiedlichen Dosierungen Vandetanib (100 mg/d und $300 \mathrm{mg} / \mathrm{d}$ ) verglichen [53]. Im Vergleich zur Docetaxel-Monotherapie war das mediane PFS nur bei einer Kombination von Docetaxel mit 100 mg/d Vandetanib signifikant verbessert (Vandetanib $100 \mathrm{mg} / \mathrm{d}$ Arm: 18,7 Wochen versus 12 Wochen bei alleiniger Docetaxel-Therapie, $\mathrm{p}=0,037$; Vandetanib 300 Arm: 17 Wochen versus alleinige Docetaxel-Therapie, $\mathrm{p}=0,23)$. Schließlich war das mediane PFS einer Erstlinientherapie bei Stadium IIIB/IV NSCLC mit Carboplatin und Paclitaxel mit $300 \mathrm{mg} / \mathrm{d}$ Vandetanib der gleichen Therapie ohne Vandetanib überlegen (24 versus 23 Wochen, $\mathrm{p}=0,098$ ) [54]. Eine Monotherapie mit Vandetanib war in dieser Studie der alleinigen Chemotherapie unterlegen. Das Gesamtüberleben war in keiner dieser Phase-II-Studien statistisch signifikant verschieden.

In Kombination mit Docetaxel führte Vandetanib bei insgesamt 1391 vorbehandelten NSCLC-Patienten zu einer signifikanten Verbesserung des progressionsfreien Überlebens (hazard ratio [HR] 0.79, p <0,001) im Vergleich zu Docetaxel allein [55]. Diese und weitere Phase-III-Studien konnten in der aktuellen Auswertung jedoch kein verbessertes Gesamtüberleben bei einer Vandetanib-Monotherapie (im Vergleich zu Erlotinib) oder in Kombination mit Docetaxel oder Pemetrexed (versus Chemo-Monotherapie) als Zweitlinientherapie zeigen [55-57]. Daher wurde der 
Antrag auf Zulassung von Vandetanib in Kombination mit Chemotherapie für NSCLC-Patienten zurückgezogen. Eine weitere Phase-III-Studie untersuchte Vandetanib versus Placebo bei NSCLC-Patienten nach Versagen eines EGFR-TKI (ZEPHYR). Eine Präsentation der Daten wird für 2010 erwartet. Hierbei wurden wie bei den oben beschriebenen Studien auch Patienten mit dominierender Plattenepithelkarzinom-Histologie eingeschlossen.

\section{BIBF1120}

$\nabla$

BIBF1120 ist ein oraler multi-TKI, der die Rezeptoren VEGFR1 - 3 sowie von PDGFR- $\alpha$ und $-\beta$ und FGFR1 - 3 lang anhaltend blockiert [39]. Möglicherweise ist die gleichzeitige Hemmung von FGFR ein Vorteil dieser Substanz, um eine Induktion von Resistenzmechanismen zumindest zu verzögern $[32,33]$. In präklinischen Studien führte eine Behandlung mit BIBF1120 zur Inhibition von Proliferation und Induktion von Apoptose in Endothelzellen, Perizyten und glatten Gefäßmuskelzellen [39]. Damit werden gleichzeitig verschiedene Zelltypen, die entscheidend zur Bildung neuer Blutgefäße, aber auch zur Gefäßreife, -stabilisierung und -funktionalität beitragen, effektiv gehemmt $[17,58,59]$. In verschiedenen Tumormodellen einschließlich NSCLC wurden zudem ein rascher und deutlicher Rückgang der Tumorperfusion und eine signifikante Hemmung des Tumorwachstums beobachtet [39].

In einer doppel-blinden Phase-II-Studie zeigte sich bei einer BIBF1120-Monotherapie in unterschiedlicher Dosierung bei 73 Patienten mit Stadium IIIB/IV NSCLC und Progress nach vorausgegangener Erst- oder Zweitlinientherapie kein signifikanter Unterschied bezüglich PFS und Ansprechen bei Dosierung von $2 \times 250 \mathrm{mg}$ BIBF1120 gegenüber einer Dosierung von $2 \times 150 \mathrm{mg}$ BIBF1120 [60]. Der insgesamt moderate Erfolg in diesem prognostisch ungünstigen Patientenkollektiv (medianes PFS 1,6 Monate; kein Patient mit Tumoransprechen, aber 35 Patienten mit Krankheitsstabilisierung) war mit Ergebnissen einer Monotherapie anderer multi-TKIs vergleichbar [52,61]. Interessant war das gute Abschneiden der Untergruppe von Patienten mit gutem Allgemeinzustand (ECOG-Status 0 oder 1: Krankheitsstabilisierung bei 59\%, PFS 2,9 Monate und Gesamtüberleben 9,5 Monate). Diese Studie bestätigte zudem eine gute Verträglichkeit von BIBF1120 mit nur wenigen Grad-3-Toxizitäten [Nausea (8\%), Erbrechen (4\%), Diarrhö (7\%), abdominelle Schmerzen (4\%) und Leberenzymerhöhung (5\%)], die bereits in Phase-I-Studien gezeigt werden konnte $[62,63]$. Es wurden keine Grad-4- oder gar Grad-5-Toxizitäten berichtet. Patienten mit Plattenepithelkarzinomen oder Hirnmetastasen waren nicht ausgeschlossen.

Auch in Kombination mit zytotoxischen Substanzen wurde BIBF1120 evaluiert. In einer Phase-I-Studie mit 20 vorbehandelten NSCLC-Patienten wurde bei einer Kombinationstherapie von BIBF1120 mit Pemetrexed ein vielversprechendes Ansprechen (1 CR, 2 PR und 8 SD) beschrieben [62]. Aktuell wird BIBF 1120 in Kombination mit Docetaxel bzw. Pemetrexed im Zweitlinien-Ansatz bei Patienten mit fortgeschrittenem NSCLC jeglicher Histologie in klinischen Phase-III-Studien untersucht.

\section{Weitere Substanzen}

$\nabla$

Zahlreiche weitere Substanzen befinden sich aktuell in klinischer Testung. Hierbei handelt es sich um unterschiedlich konstruierte Antikörper, Fusionsproteine des VEGF-Rezeptors und des huma- nen IgG1 Fc Fragments und weitere multi-Tyrosinkinase-Inhibitoren. Aktuelle Phase-III-Studien rekrutieren Patienten mit fortgeschrittenem oder metastasiertem NSCLC sowohl im Rahmen einer Erstlinientherapie (z.B. Cediranib oder Motesanib, jeweils in Kombination mit Carboplatin und Paclitaxel) als auch einer Zweitlinientherapie (z.B. Aflibercept in Kombination mit Docetaxel).

\section{Vascular Disrupting Agents \\ $\nabla$}

Neben anti-angiogenen Substanzen werden niedermolekulare gefäßzerstörende Substanzen (VDAs) entwickelt, die direkt endothelzellzerstörend wirken sollen [64]. Damit unterscheidet sich prinzipiell das intendierte Ziel der VDAs deutlich von demjenigen anti-angiogener Substanzen. Hypothetisch führt dies zu unterschiedlich zu erwartenden klinischen Konsequenzen: Während anti-angiogene Substanzen vornehmlich neue, „unreife“ Gefäße angreifen, ist das intendierte Ziel von VDAs die Zerstörung etablierter, „reifer“ Blutgefäße mit dem Ziel eines Perfusion-Stopps des Tumors. Die beabsichtigte Konsequenz dieser Aktivitäten ist eine Stasis der Durchblutung und damit Unterbindung der Blutversorgung, was sekundär zu umfangreichen Nekrosen und Destruktion des Tumorzentrums führt. Während dieses Wirkprinzip recht klar definiert werden kann, so sind die durch VDAs tatsächlich ausgelösten Effekte in der Klinik und auch in präklinischen Modellen schwierig zu evaluieren. Präklinische Daten deuten darauf hin, dass verschiedene Pathomechanismen wie Hemmung von Mikrotubuli und Erhöhung der Gefäßpermeabilität mit Komprimierung der Gefäße bei der Wirkung von VDAs involviert sein könnten. In präklinischen Modellen zeigte sich in der Tat eine zentrale Einschmelzung subkutaner Tumoren, während die Tumorperipherie aufgrund Mitversorgung durch umliegende Stromagefäße meist vital blieb [64,65]. Diese Beobachtung könnte eine Kombination mit anti-angiogenen Substanzen interessant machen. Letztere sollten besonders in der Tumorperipherie eine gute Aktivität erwarten lassen und könnten eine Repopulation des Tumorzentrums nach VDA-Therapie mit der Induktion von Angiogenese als hypothetischen Resistenzmechanismus verhindern $[31,66]$. Im Tiermodell konnte eine verbesserte Wirkung einer Kombinationstherapie von VDAs mit anti-VEGF-Antikörpern gegenüber einer Monotherapie bereits gezeigt werden [67].

Trotz der unterschiedlichen Therapieprinzipien haben VDAs und anti-angiogene Therapeutika auch einige Gemeinsamkeiten, da beide letztlich einen Untergang von Endothelzellen und sekundär auch von Tumorzellen bewirken sollen. Um die Effektivität von VDAs mit anti-angiogenen Substanzen vergleichen zu können, müssen daher die Ergebnisse größerer klinischer Studien abgewartet werden. Verschiedene niedermolekulare Substanzen sind als VDAs entwickelt worden ( Tab. 3 ), von denen die Combretastatine und die Flavonoide (ASA404) die aktuell am besten klinisch entwickelten Substanzklassen sind.

\section{Combretastatin A4 Phosphat \\ $\nabla$}

Tubulin-bindende Substanzen führen zu einer Zerstörung des endothelialen Zytoskeletts durch Depolymerisierung von Mikrotubuli. Combretastatine sind strukturell mit dem klassischen Tubulin-bindenden Colchicin verwandt, welches selbst zu starke Toxizitäten aufweist [64]. Im Tiermodell zeigte Combretastatin A4 
Tab. 3 Übersicht über VDAs in klinischen Studien (aus [83], nach [69]).

\begin{tabular}{|c|c|c|c|c|c|c|}
\hline Substanz & $\begin{array}{l}\text { Substanz- } \\
\text { klasse }\end{array}$ & Zielstruktur & $\begin{array}{l}\text { Aktuelle } \\
\text { Schwerpunkte }\end{array}$ & $\begin{array}{l}\text { Aktuell in } \\
\text { klinischen Studien }\end{array}$ & $\begin{array}{l}\text { Wichtige } \\
\text { Nebenwirkungen }\end{array}$ & Literatur \\
\hline $\mathrm{ADH}-1$ & $\begin{array}{l}\text { zyklisches } \\
\text { Pentapeptid }\end{array}$ & $\mathrm{N}$-Cadherin & verschiedene & Phase I/II & $\begin{array}{l}\text { kardiale Ischämie } \\
\text { Flush } \\
\text { Fatigue } \\
\text { Hypertonie } \\
\text { Nausea } \\
\text { pulmonale Hämorrhagie } \\
\text { Geschmackstörungen }\end{array}$ & {$[91,92]$} \\
\hline AVE8062 & $\begin{array}{l}\text { CA4-Analo- } \\
\text { gon }\end{array}$ & Tubulin & Sarkom & Phase II/III & $\begin{array}{l}\text { transiente myokardiale } \\
\text { Ischämie } \\
\text { Hypotonie } \\
\text { transiente neurologische } \\
\text { Symptome }\end{array}$ & [93] \\
\hline $\begin{array}{l}\text { Combretastatin } \\
\text { A4-Phosphat } \\
\text { (CA4P, } \\
\text { Zybrestat }^{\top M} \text { ) }\end{array}$ & $\begin{array}{l}\text { Colchicin- } \\
\text { ähnlich }\end{array}$ & Tubulin & $\begin{array}{l}\text { Schilddrüsenkarzinom } \\
\text { NSCLC } \\
\text { Sarkom }\end{array}$ & Phase II/III & $\begin{array}{l}\text { kardiale Ischämie } \\
\text { reversible Ataxie } \\
\text { Hypotonie } \\
\text { Tumorschmerzen } \\
\text { Thrombozytopenie } \\
\text { Hypotonie } \\
\text { intestinale Ischämie } \\
\text { vagale Synkopen } \\
\text { motorische Neuropathie } \\
\text { Dyspnoe }\end{array}$ & {$[94,95]$} \\
\hline $\begin{array}{l}\text { DMXAA } \\
\text { (Vadimezan) }\end{array}$ & Flavonoid & TNF- $\alpha$ & $\begin{array}{l}\text { NSCLC } \\
\text { Prostatakarzinom }\end{array}$ & Phase III & $\begin{array}{l}\text { Konfusion } \\
\text { myokardiale Ischämie } \\
\text { Tremor } \\
\text { Kopfschmerzen } \\
\text { visuelle Störungen } \\
\text { QTc-Verlängerung } \\
\text { reversible Urin-Inkontinenz } \\
\text { Angstgefühl }\end{array}$ & {$[96,97]$} \\
\hline TZT-1027 & $\begin{array}{l}\text { Dolostatin-10 } \\
\text { Analog }\end{array}$ & Tubulin & $\begin{array}{l}\text { NSCLC } \\
\text { Sarkom }\end{array}$ & Phase II & $\begin{array}{l}\text { Neutropenie } \\
\text { Phlebitis } \\
\text { periphere Neuropathie } \\
\text { Nausea/Erbrechen } \\
\text { Fatigue } \\
\text { Tumorschmerzen } \\
\text { Schmerzen im Infusions- } \\
\text { Arm lleus }\end{array}$ & {$[98,99]$} \\
\hline ZD6126 & $\begin{array}{l}\text { Colchicin- } \\
\text { ähnlich }\end{array}$ & Tubulin & $\begin{array}{l}\text { Nierenzellkarzinom } \\
\text { kolorektal }\end{array}$ & Phase II & $\begin{array}{l}\text { myokardiale Ischämie } \\
\text { verminderte LVEF } \\
\text { pulmonale Embolie } \\
\text { Fatigue }\end{array}$ & {$[100,101]$} \\
\hline
\end{tabular}

Phosphat (CA4P) eine gute Aktivität mit signifikanter Reduktion der Perfusion und einem fast vollständigen, irreversiblen Gefäßverschluss $[64,68]$. In Phase I Studien mit unterschiedlicher Dosierung und Applikation [69] zeigte eine CA4P-Monotherapie bei soliden Tumoren eine insgesamt sehr gute Verträglichkeit. Dosislimitierende Nebenwirkungen waren Darmischämien, Tumorschmerzen, vasovagale Synkopen, Neuropathien, reversible Ataxien, kardiale Ischämien und Dyspnoe. Zudem wurde CA4P in Kombination mit Carboplatin untersucht [70]. Als dosislimitierende Toxizität wurden Thrombozytopenien beobachtet. Bei Patienten mit Stadium IIIB/IV NSCLC wird CA4P derzeit in einer Phase-II-Studie in Kombination mit Carboplatin, Paclitaxel und Bevacizumab als Erstlinienansatz geprüft.

\section{Flavonoide}

Flavonessigsäure (FAA) und ihre Derivate (z.B. 5,6-Dimethylxanthenon-4-Essigsäure, ASA404) induzieren ebenfalls hämorrhagische Nekrosen über einen bisher nicht vollständig aufgeklärten Mechanismus [71]. In klinischen Phase-I-Studien wurden dosislimitierende Nebenwirkungen wie reversible Urin-Inkontinenz, Sehstörungen (verschwommenes Farbensehen, Photophobie), Angstgefühle und mehrere asymptomatische transiente QT-Verlängerungen registriert [69]. In einer Phase-II-Studie bei $73 \mathrm{~Pa}-$ tienten mit Stadium IIIB/IV NSCLC wurde durch Addition von ASA404 $\left(1200 \mathrm{mg} / \mathrm{m}^{2}\right) \mathrm{zu}$ einer Therapie mit Carboplatin (AUC 6) und Paclitaxel $\left(175 \mathrm{mg} / \mathrm{m}^{2}\right)$ eine Verbesserung des Ansprechens (31\% versus $22 \%$ ) erreicht [72]. Zudem wurden durch Addition von ASA404 die mediane PFS (5,4 versus 4,4 Monate) und das Gesamtüberleben von (14,0 versus 8,8 Monate) gesteigert, was jedoch nicht signifikant war. Die Verträglichkeit beider Re- 
gime war vergleichbar. Interessanterweise wurden letale Blutungsereignisse, wie sie bei der Kombination von VEGF-Antikörpern mit zytotoxischer Therapie bei einigen Patienten beobachtet wurden, nicht berichtet [72]. Derzeit wird ASA404 beim fortgeschrittenen oder metastasierten NSCLC in Phase-III-Studien als Bestandteil einer Erstlinientherapie (in Kombination mit Carboplatin und Paclitaxel) oder als Zweitlinien-Monotherapie (im Vergleich gegen Docetaxel) evaluiert.

\section{Biomarker}

Da verschiedene Faktoren zur Regulation der Angiogenese und Gefäßstabilität des jeweiligen Tumors beitragen können, wäre es sehr sinnvoll, möglichst geeignete Patienten für die Behandlung mit einem bestimmten Inhibitor zu präselektionieren. Hilfreich wäre diesbezüglich die Identifikation möglicher prädiktiver Marker, die mit dem Ansprechen auf eine Therapie korrelieren. Prinzipiell können molekulare Marker in Tumorbiopsaten, Serum oder zirkulierende Zellen im peripheren Blut detektiert werden [73]. Bisherige klinische Studien haben keinen verlässlichen prädiktiven Marker identifizieren können, wobei nur bei einem Teil der klinischen Studien ein Biomarkerprogramm überhaupt Bestandteil war. In der ECOG4599-Studie hatten Patienten mit erniedrigter prätherapeutischer ICAM-Konzentration im Bevacizumab-Arm ein signifikant verbessertes PFS $(p<0,001)$ im Vergleich zur alleinigen Kombinationschemotherapie [74]. Indikativ auf ein signifikant verbessertes Gesamtüberleben war allein ein Abfall von E-Selectin $\leq 5,35 \mathrm{ng} / \mathrm{mL}$ unter Therapie ( $\mathrm{p}=0,02$ ), während bei prätherapeutischen Serumkonzentrationen von ICAM, VEGF, bFGF und E-Selectin hier keine signifikante Assoziation gefunden wurde [74]. In der AVAiL-Studie korrelierten erniedrigte Serumkonzentrationen von ICAM, VCAM, bFGF und VEGF mit verbesserter Prognose aber nicht mit verbessertem Überleben im Bevacizumab-Therapiearm [75]. Aktuell werden sehr unterschiedliche mögliche Marker untersucht: Basierend auf Erkenntnissen aus präklinischen Studien werden Expression und Phosphorylierung von angiogenen Rezeptoren (z.B. VEGFR), Gefäßdichte oder Hinweise auf endotheliale Umbauvorgänge und -schädigungen wie zirkulierende Adhäsionsmoleküle oder zirkulierende Endothelzellen als mögliche Prädiktoren für eine antiangiogene Therapie evaluiert. Um eine Patientensubpopulation mit möglichst gutem Ansprechen auf Bevacizumab als primären Endpunkt zu identifizieren, wird aktuell eine Phase-II-Studie bei NSCLC-Patienten und einer Therapie mit Carboplatin-basierter Kombinationschemotherapie mit Bevacizumab (7,5 mg/kg oder $15 \mathrm{mg} / \mathrm{kg}$ ) und regelmäßigen Serumanalysen durchgeführt (ABIGAIL). Für VDAs gibt es bisher keine klinischen Daten bezüglich möglicher Prädiktoren. Alternativ werden radiologische Methoden zur Gefäßdarstellung und Durchblutung (z.B. DCE-MRT, PET) entwickelt.

Auch wenn ein Konsensus über wichtige Fragen wie Lagerung, Wahl der Analysemethode, Verarbeitung der Proben, Auswahl der Reagenzien und Interpretation der Ergebnisse zumeist noch aussteht [76,77], so sollten doch molekulare Begleituntersuchungen mit dem Ziel der Identifikation prädiktiver Faktoren immanente Bestandteile von klinischen Studien sein. Gerade bei der zunehmenden Zahl von neuen Substanzen mit definiertem molekularem Ziel ist eine Selektion von Patienten anhand von Prädiktoren anzustreben, um eine individuell erfolgversprechende Therapieplanung zu ermöglichen. Bezüglich des aktuellen Forschungsstandes verweisen wir auf aktuelle Übersichtsartikel $[73,78,79]$.

\section{Ausblick \\ $\nabla$}

Verschiedene Therapieansätze sind zur Hemmung und Zerstörung von Blutgefäßen im Tumor entwickelt worden mit dem Ziel eines sekundären Tumorzelluntergangs. Mit Bevacizumab ist bereits eine anti-angiogene Substanz in Kombination mit Chemotherapie für die Erstlinien-Behandlung des NSCLC zugelassen. Zahlreiche weitere Substanzen einschließlich Multi-TKIs befinden sich aktuell in klinischer Testung. Als weitere Substanzgruppe werden VDAs als Monotherapie und in Kombination mit Chemotherapeutika, Radiotherapie oder anti-angiogenen Substanzen evaluiert. Insgesamt zeigt sich, dass die Wirkung anti-angiogener Substanzen deutlich komplexer ist, als initial angenommen. Neben anti-endothelialen Effekten wurden auch Auswirkungen auf den Gefäßtonus, die Mobilisation endothelialer Vorläuferzellen (endothelial progenitor cells, EPCs) und eine direkte Anti-Tumorwirkung beschrieben [80]. Präklinische Studien deuteten zudem an, dass einzelne zytotoxische Substanzen in unterschiedlichem Ausmaß EPCs mobilisieren, was durch vorherige anti-VEGF-Therapie blockiert werden konnte [81]. Aufgrund des meist akuten Effekts von VDAs auf die Durchblutung des Tumors ist hier die Sequenz bei Kombination mit Chemotherapeutika besonders wichtig. Im Mausmodell zeigte eine Applikation von Paclitaxel vor dem VDA ZD6126 keinen signifikanten zusätzlichen Nutzen, während bei einer Applikation nach ZD6126 ein ausgeprägter Anti-Tumoreffekt beobachtet wurde [82]. Insgesamt ist in den nächsten Jahren von einer deutlichen Erweiterung der therapeutischen Palette und möglicherweise auch der therapeutischen Schemata bei der Behandlung des NSCLC auszugehen.

Für den Kliniker bedeutet dies allerdings auch die Notwendigkeit kontinuierlicher Weiterbildung, um die teilweise sehr komplexen Therapieansätze verstehen und neue Substanzen korrekt einsetzen zu können.

Zudem muss die Entwicklung und Identifikation prädiktiver Marker gefördert werden, um Patienten für einen möglichst erfolgversprechenden Therapieansatz präselektionieren zu können. Auch radiologische Verfahren wie DCE-MRT zur Abschätzung der Tumordurchblutung könnten als Monitor-Verfahren Bedeutung erlangen. Daher sollte die Implementierung von molekularen oder bildgebenden Begleituntersuchungen bei der Konzeption und Durchführung klinischer Studien berücksichtigt werden.

\section{Interessenskonflikte}

$\nabla$

N. Reinmuth erhielt Honoraria von Boehringer Ingelheim Pharma GmbH \& Co. KG. und Novartis Deutschland GmbH. M. Steins erhielt Honoraria von Boehringer Ingelheim Pharma GmbH \& Co. KG und Roche Deutschland Holding GmbH. M. Thomas erhielt Honoraria von Roche Deutschland Holding GmbH, Boehringer Ingelheim Pharma GmbH \& Co. KG und AstraZeneca GmbH. 


\section{Literatur}

1 Thomas M, Rube C, Hoffknecht P et al. Effect of preoperative chemoradiation in addition to preoperative chemotherapy: a randomised trial in stage III non-small-cell lung cancer. Lancet Oncol 2008; 9: 636648

2 Mountain CF. Revisions in the International System for Staging Lung Cancer. Chest 1997; 111: 1710-1717

3 Parkin DM, Pisani P, Ferlay J. Global cancer statistics. CA Cancer J Clin 1999; 49: 33-64, 31

4 Souhami RL, Law K. Longevity in small cell lung cancer. A report to the Lung Cancer Subcommittee of the United Kingdom Coordinating Committee for Cancer Research. Br J Cancer 1990; 61: 584- 589

5 Hanahan D, Weinberg RA. The hallmarks of cancer. Cell 2000; 100 : $57-70$

6 Folkman J. Tumor angiogenesis: therapeutic implications. N Engl J Med 1971; 285: 1182 - 1186

7 Reinmuth N, Stoeltzing O, Liu W et al. Endothelial survival factors as targets for antineoplastic therapy. Cancer J 2001; 7 Suppl 3: S109S119

8 Hicklin DJ, Ellis LM. Role of the vascular endothelial growth factor pathway in tumor growth and angiogenesis. J Clin Oncol 2005; 23 : $1011-1027$

9 Korff T, Kimmina S, Martiny-Baron G, Augustin HG. Blood vessel maturation in a 3-dimensional spheroidal coculture model: direct contact with smooth muscle cells regulates endothelial cell quiescence and abrogates VEGF responsiveness. FASEB J 2001; 15: 447-457

10 Yano S, Nishioka Y, Goto H, Sone S. Molecular mechanisms of angiogenesis in non-small cell lung cancer, and therapeutics targeting related molecules. Cancer Sci 2003; 94: 479-485

11 Dome B, Timar J, Dobos J et al. Identification and clinical significance of circulating endothelial progenitor cells in human non-small cell lung cancer. Cancer Res 2006; 66: 7341 - 7347

12 Mancuso P, Burlini A, Pruneri G et al. Resting and activated endothelial cells are increased in the peripheral blood of cancer patients. Blood 2001; 97: 3658-3661

13 Holash J, Maisonpierre PC, Compton D et al. Vessel cooption, regression, and growth in tumors mediated by angiopoietins and VEGF. Science 1999; 284: $1994-1998$

14 Reinmuth $N$, Piegelbrock E, Raedel $M$ et al. Prognostic significance of vessel architecture and vascular stability in non-small cell lung cancer. Lung Cancer 2007; 55: 53-60

15 Mandarino LJ, Sundarraj N, Finlayson J, Hassell HR. Regulation of fibronectin and laminin synthesis by retinal capillary endothelial cells and pericytes in vitro. Exp Eye Res 1993; 57: 609-621

16 Cleaver O, Melton DA. Endothelial signaling during development. Nat Med 2003; 9: 661 - 668

17 Reinmuth $N$, Liersch R, Raedel $M$ et al. Combined anti-PDGFRalpha and PDGFRbeta targeting in non-small cell lung cancer. Int J Cancer 2009; 124: 1535 - 1544

18 Eberhard A, Kahlert S, Goede $V$ et al. Heterogeneity of angiogenesis and blood vessel maturation in human tumors: implications for antiangiogenic tumor therapies. Cancer Res 2000; 60: 1388-1393

19 Carmeliet $P$, Jain RK. Angiogenesis in cancer and other diseases. Nature 2000; 407: 249-257

20 Folkman J. Angiogenesis. Annu Rev Med 2006; 57: 1-18

21 Chaplin DJ, Dougherty GJ. Tumour vasculature as a target for cancer therapy. Br J Cancer 1999; 80 Suppl 1: 57-64

22 Mueller MM, Fusenig NE. Friends or foes - bipolar effects of the tumour stroma in cancer. Nat Rev Cancer 2004; 4: 839-849

23 Paez-Ribes $M$, Allen E, Hudock J et al. Antiangiogenic therapy elicits malignant progression of tumors to increased local invasion and distant metastasis. Cancer Cell 2009; 15: 220-231

24 Ferrara N, Gerber HP, LeCouter J. The biology of VEGF and its receptors. Nat Med 2003; 9: 669-676

25 Ma J, Waxman DJ. Combination of antiangiogenesis with chemotherapy for more effective cancer treatment. Mol Cancer Ther 2008; 7: $3670-3684$

26 Fontanini G, Vignati S, Boldrini L et al. Vascular endothelial growth factor is associated with neovascularization and influences progression of non-small cell lung carcinoma. Clin Cancer Res 1997; 3: 861 865

27 Reck M, Pawel J von, Zatloukal P et al. Phase III trial of cisplatin plus gemcitabine with either placebo or bevacizumab as first-line therapy for nonsquamous non-small-cell lung cancer: AVAil. J Clin Oncol 2009; 27: $1227-1234$
28 Sandler A, Gray R, Perry MC et al. Paclitaxel-carboplatin alone or with bevacizumab for non-small-cell lung cancer. N Engl J Med 2006; 355 : $2542-2550$

29 Jain RK, Booth MF. What brings pericytes to tumor vessels? J Clin Invest 2003; 112: $1134-1136$

30 Ebos JM, Lee CR, Kerbel RS. Tumor and host-mediated pathways of resistance and disease progression in response to antiangiogenic therapy. Clin Cancer Res 2009; 15: 5020-5025

31 Shaked Y, Ciarrocchi A, Franco $M$ et al. Therapy-induced acute recruitment of circulating endothelial progenitor cells to tumors. Science 2006; 313: $1785-1787$

32 Casanovas O, Hicklin DJ, Bergers G, Hanahan D. Drug resistance by evasion of antiangiogenic targeting of VEGF signaling in late-stage pancreatic islet tumors. Cancer Cell 2005; 8: 299-309

33 Donnem T, Al-Shibli K, Al-Saad S, Busund LT, Bremnes RM. Prognostic impact of fibroblast growth factor 2 in non-small cell lung cancer: coexpression with VEGFR-3 and PDGF-B predicts poor survival. J Thorac Oncol 2009; 4: 578-585

34 Johnson DH, Fehrenbacher L, Novotny WF et al. Randomized phase II trial comparing bevacizumab plus carboplatin and paclitaxel with carboplatin and paclitaxel alone in previously untreated locally advanced or metastatic non-small-cell lung cancer. J Clin Oncol 2004; 22: $2184-2191$

35 Socinski MA, Langer CJ, Huang JE et al. Safety of Bevacizumab in Patients With Non-Small-Cell Lung Cancer and Brain Metastases. J Clin Oncol 2009; 27: 5255-5261

36 Rohr UP, Augustus S, Lasserre SF, Compton P, Huang J. Safety of bevacizumab in patients with metastases to the central nervous system. J Clin Oncol 2009; 27: a2007

37 Ramalingam SS, Dahlberg SE, Langer CJ et al. Outcomes for elderly, advanced-stage non small-cell lung cancer patients treated with bevacizumab in combination with carboplatin and paclitaxel: analysis of Eastern Cooperative Oncology Group Trial 4599. J Clin Oncol 2008; 26: $60-65$

38 Leighl NB, Zatloukal P, Mezger J et al. Efficacy and safety of first-line bevacizumab (Bv) and cisplatin/gemcitabine (CG) in elderly patients (pts) with advanced non-small cell lung cancer (NSCLC) in the B017704 study (AVAiL). J Clin Oncol 2009; 27: a8050

39 Hilberg F, Roth GJ, Krssak $M$ et al. BIBF 1120: triple angiokinase inhibitor with sustained receptor blockade and good antitumor efficacy. Cancer Res 2008; 68: 4774-4782

40 Wilhelm SM, Carter C, Tang L et al. BAY 43-9006 exhibits broad spectrum oral antitumor activity and targets the RAF/MEK/ERK pathway and receptor tyrosine kinases involved in tumor progression and angiogenesis. Cancer Res 2004; 64: 7099-7109

41 Schiller JH, Lee JW, Hanna NH, Traynor AM, Carbone DP. A randomized discontinuation phase II study of sorafenib versus placebo in patients with non-small cell lung cancer who have failed at least two prior chemotherapy regimens: E2501. J Clin Oncol 2008; 26: a8014

42 Scagliotti G, Pawel J von, Reck $M$ et al. Phase III trial comparing carboplatin and paclitaxel with or without sorafenib in chemonaive patients with stage IIIB (with effusion) or IV non-small cell lung cancer. In, 1st IASLC-ESMO European Lung Cancer Conference. Geneva (Switzerland): 2008

43 Horn L, Sandler A. Epidermal growth factor receptor inhibitors and antiangiogenic agents for the treatment of non-small cell lung cancer. Clin Cancer Res 2009; 15: 5040-5048

44 Mendel $D B$, Laird $A D$, Xin $X$ et al. In vivo antitumor activity of SU11248, a novel tyrosine kinase inhibitor targeting vascular endothelial growth factor and platelet-derived growth factor receptors: determination of a pharmacokinetic/pharmacodynamic relationship. Clin Cancer Res 2003; 9: 327-337

45 Socinski MA, Novello S, Brahmer JR et al. Multicenter, phase II trial of sunitinib in previously treated, advanced non-small-cell lung cancer. J Clin Oncol 2008; 26: 650-656

46 Brahmer JR, Govindan R, Novello S et al. Efficacy and safety of continuous daily sunitinib dosing in previously treated advanced non-small cell lung cancer (NSCLC): Results from a phase II study. J Clin Oncol 2007; 25: a7542

47 Reck M, Frickhofen N, Gatzemeier U et al. A phase I dose escalation study of sunitinib in combination with gemcitabine + cisplatin for advanced non-small cell lung cancer (NSCLC). J Clin Oncol 2007; 25: a18057 
48 Wedge SR, Ogilvie DJ, Dukes M et al. ZD6474 inhibits vascular endothelial growth factor signaling, angiogenesis, and tumor growth following oral administration. Cancer Res 2002; 62: 4645 - 4655

49 Ciardiello F, Bianco R, Caputo R et al. Antitumor activity of ZD6474, a vascular endothelial growth factor receptor tyrosine kinase inhibitor, in human cancer cells with acquired resistance to antiepidermal growth factor receptor therapy. Clin Cancer Res 2004; 10: 784-793

50 Santoro M, Melillo RM, Carlomagno F, Fusco A, Vecchio G. Molecular mechanisms of RET activation in human cancer. Ann N Y Acad Sci 2002; 963: 116-121

51 Kiura K, Nakagawa K, Shinkai T et al. A randomized, double-blind, phase Ila dose-finding study of Vandetanib (ZD6474) in Japanese patients with non-small cell lung cancer. J Thorac Oncol 2008; 3: 386 393

52 Natale RB, Bodkin D, Govindan $R$ et al. Vandetanib versus gefitinib in patients with advanced non-small-cell lung cancer: results from a two-part, double-blind, randomized phase ii study. J Clin Oncol 2009; 27: $2523-2529$

53 Heymach JV, Johnson BE, Prager D et al. Randomized, placebo-controlled phase II study of vandetanib plus docetaxel in previously treated non small-cell lung cancer. J Clin Oncol 2007; 25: 4270-4277

54 Heymach JV, Paz-Ares L, De Braud F et al. Randomized phase II study of vandetanib alone or with paclitaxel and carboplatin as first-line treatment for advanced non-small-cell lung cancer. J Clin Oncol 2008; 26: $5407-5415$

55 Herbst RS, Sun Y, Korfee S et al. Vandetanib plus docetaxel versus docetaxel as second-line treatment for patients with advanced nonsmall cell lung cancer (NSCLC): A randomized, double-blind phase III trial (ZODIAC). J Clin Oncol 2009; 27: cra8003

56 DeBoer R, Arrieta Ó, Gottfried M et al. Vandetanib plus pemetrexed versus pemetrexed as second-line therapy in patients with advanced non-small cell lung cancer (NSCLC): A randomized, double-blind phase III trial (ZEAL). J Clin Oncol 2009; 27: a8010

57 Natale RB, Thongprasert S, Greco FA et al. Vandetanib versus erlotinib in patients with advanced non-small cell lung cancer (NSCLC) after failure of at least one prior cytotoxic chemotherapy: A randomized, double-blind phase III trial (ZEST). J Clin Oncol 2009; 27: a8009

58 Sennino B, Falcon BL, McCauley D et al. Sequential loss of tumor vessel pericytes and endothelial cells after inhibition of platelet-derived growth factor B by selective aptamer AX102. Cancer Res 2007; 67: $7358-7367$

59 Bergers G, Song S, Meyer-Morse N, Bergsland E, Hanahan D. Benefits of targeting both pericytes and endothelial cells in the tumor vasculature with kinase inhibitors. J Clin Invest 2003; 111: 1287-1295

60 Pawel J von, Kaiser R, Eschbach C et al. A double blind phase II study of BIBF 1,120 in patients suffering from relapsed advanced non-small cell lung cancer (NSCLC). J Clin Oncol 2007; 25: a7635

61 Gatzemeier U, Blumenschein G, Fosella F et al. Phase II trial of singleagent sorafenib in patients with advanced non-small cell lung carcinoma. J Clin Oncol 2006; 24: a7002

62 Hanna N, Ellis P, Stopfer P, Shapiro D, Gyorffy S. A Phase I study of continuous oral treatment with the triple angiokinase inhibitor BIBF 1120 together with pemetrexed in previously treated patients with non-small cell lung cancer: P3-091. J Thoracic Oncol 2007; 2: S717

63 Mross KB, Gmehling D, Frost A et al. A clinical Phase I, pharmacokinetic (PK), and pharmacodynamic study of twice daily BIBF 1120 in advanced cancer patients. J Clin Oncol 2005; 23: a3031

64 Tozer GM, Kanthou C, Baguley BC. Disrupting tumour blood vessels. Nat Rev Cancer 2005; 5: 423-435

65 Blakey DC, Westwood FR, Walker M et al. Antitumor activity of the novel vascular targeting agent ZD6126 in a panel of tumor models. Clin Cancer Res 2002; 8: 1974-1983

66 Lyden D, Hattori K, Dias $S$ et al. Impaired recruitment of bone-marrow-derived endothelial and hematopoietic precursor cells blocks tumor angiogenesis and growth. Nat Med 2001; 7: 1194-1201

67 Siemann DW, Shi W. Dual targeting of tumor vasculature: combining Avastin and vascular disrupting agents (CA4P or OXi4503). Anticancer Res 2008; 28: 2027-2031

68 Dark GG, Hill SA, Prise VE et al. Combretastatin A-4, an agent that displays potent and selective toxicity toward tumor vasculature. Cancer Res 1997; 57: 1829-1834

69 Hinnen P, Eskens FA. Vascular disrupting agents in clinical development. Br J Cancer 2007; 96: 1159-1165
70 Bilenker JH, Flaherty KT, Rosen $M$ et al. Phase I trial of combretastatin a-4 phosphate with carboplatin. Clin Cancer Res 2005; 11: $1527-$ 1533

71 Zwi LJ, Baguley BC, Gavin JB, Wilson WR. Correlation between immune and vascular activities of xanthenone acetic acid antitumor agents. Oncol Res 1994; 6: 79-85

72 McKeage MJ, Pawel J von, Reck $M$ et al. Randomised phase II study of ASA404 combined with carboplatin and paclitaxel in previously untreated advanced non-small cell lung cancer. Br J Cancer 2008; 99: $2006-2012$

73 Jain RK, Duda DG, Sorensen AG. Emerging Paradigms and Potential Biomarkers of Response and Resistance in Antiangiogenic Therapy of Cancer. Educational Book ASCO, 2009: 716 - 721

74 Dowlati A, Gray R, Sandler AB, Schiller JH, Johnson DH. Cell adhesion molecules, vascular endothelial growth factor, and basic fibroblast growth factor in patients with non-small cell lung cancer treated with chemotherapy with or without bevacizumab - an Eastern Cooperative Oncology Group Study. Clin Cancer Res 2008; 14: 1407 1412

75 Leighl N, Reck M, de Haas S et al. Analysis of biomarkers (BMs) in the AVAiL phase III randomised study of first-line Bevacizumab (Bv) with cisplatin-gemcitabine (CG) in patients (pts) with non-small cell lung cancer (NSCLC). Eur J Cancer 2009; Suppl, Vol. 7: 558

76 Vermeulen PB, Gasparini G, Fox SB et al. Second international consensus on the methodology and criteria of evaluation of angiogenesis quantification in solid human tumours. Eur J Cancer 2002; 38: 1564 1579

77 Mandrekar SJ, Sargent DJ. Clinical trial designs for predictive biomarker validation: theoretical considerations and practical challenges. J Clin Oncol 2009; 27: 4027-4034

78 Reinmuth N, Thomas M, Meister M, Schnabel PA, Kreuter M. Current data on predictive markers for anti-angiogenic therapy in thoracic cancers. submitted to Eur Res J

79 Cai W, Chen X. Multimodality molecular imaging of tumor angiogenesis. J Nucl Med 2008; 49 Suppl 2: 113S-128S

80 Ellis LM, Hicklin DJ. VEGF-targeted therapy: mechanisms of anti-tumour activity. Nat Rev Cancer 2008; 8: 579-591

81 Shaked Y, Henke E, Roodhart JM et al. Rapid chemotherapy-induced acute endothelial progenitor cell mobilization: implications for antiangiogenic drugs as chemosensitizing agents. Cancer Cell 2008; 14 $263-273$

82 Martinelli M, Bonezzi K, Riccardi $E$ et al. Sequence dependent antitumour efficacy of the vascular disrupting agent ZD6126 in combination with paclitaxel. Br J Cancer 2007; 97: 888-894

83 Reinmuth N, Bischoff H, Kindermann M, Steins M, Thomas M. Vascular Disrupting Agents beim nicht-kleinzelligen Lungenkarzinom. Atemwegs- und Lungenkrankheiten 2009; 35: 471 - 478

84 Laurie SA, Gauthier I, Arnold A et al. Phase I and pharmacokinetic study of daily oral AZD2171, an inhibitor of vascular endothelial growth factor tyrosine kinases, in combination with carboplatin and paclitaxel in patients with advanced non-small-cell lung cancer: the National Cancer Institute of Canada clinical trials group. J Clin Oncol 2008; 26: $1871-1878$

85 Heymach J, Paz-Ares L, De Braud F et al. Randomized phase II study of vandetanib (VAN) alone or in combination with carboplatin and paclitaxel (CP) as first-line treatment for advanced non-small cell lung cancer (NSCLC). J Clin Oncol 2007; 25: a7544

86 Rizvi NA, Kris MG, Miller VA et al. Activity of XL647 in clinically selected NSCLC patients (pts) enriched for the presence of EGFR mutations: Results from Phase 2. J Clin Oncol 2008; 26: a8053

87 Schiller JH, Larson T, Ou SH et al. Efficacy and safety of axitinib in patients with advanced non-small-cell lung cancer: results from a phase II study. J Clin Oncol 2009; 27: 3836-3841

88 Schiller JH, Flaherty KT, Redlinger $M$ et al. Sorafenib combined with carboplatin/paclitaxel for advanced non-small cell lung cancer: A phase I subset analysis. J Clin Oncol 2006; 24: a7194

89 Latreille J, Batist G, Laberge F et al. Phase I/II trial of the safety and efficacy of AE-941 (Neovastat) in the treatment of non-small-cell lung cancer. Clin Lung Cancer 2003; 4: 231-236

90 Miller VA, Wakelee HA, Lara PN et al. Activity and tolerance of XL647 in NSCLC patients with acquired resistance to EGFR-TKIs: Preliminary results of a phase II trial. J Clin Oncol 2008; 26: a8028 
91 Stewart DJ, Jonker DJ, Goel R et al. Final clinical and pharmacokinetic (PK) results from a phase 1 study of the novel $\mathrm{N}$-cadherin ( $\mathrm{N}$-cad) antagonist, Exherin (ADH-1), in patients with refractory solid tumors stratified according to N-cad expression. J Clin Oncol 2006; 24: a3016

92 Sessa C, Perotti A, Maur M et al. An enriched phase I, pharmacokinetic and pharmacodynamic study of the N-cadherin (NCAD) cyclic competitive binder exherin (ADH-1) in patients with solid tumors. J Clin Oncol 2006; 24: a3042

93 Tolcher AW, Forero L, Celio P et al. Phase I, pharmacokinetic, and DCEMRI correlative study of AVE8062A, an antivascular combretastatin analogue, administered weekly for 3 weeks every 28-days. J Clin Oncol 2003; 22: a834

94 Rustin GJ, Galbraith SM, Anderson $\mathrm{H}$ et al. Phase I clinical trial of weekly combretastatin A4 phosphate: clinical and pharmacokinetic results. J Clin Oncol 2003; 21: 2815-2822

95 Stevenson JP, Rosen M, Sun $W$ et al. Phase I trial of the antivascular agent combretastatin A4 phosphate on a 5-day schedule to patients with cancer: magnetic resonance imaging evidence for altered tumor blood flow. J Clin Oncol 2003; 21: 4428-4438

96 Dowlati A, Robertson K, Cooney $M$ et al. A phase I pharmacokinetic and translational study of the novel vascular targeting agent combretastatin a-4 phosphate on a single-dose intravenous schedule in patients with advanced cancer. Cancer Res 2002; 62: 3408 - 3416

97 Cooney MM, Radivoyevitch T, Dowlati A et al. Cardiovascular safety profile of combretastatin a 4 phosphate in a single-dose phase I study in patients with advanced cancer. Clin Cancer Res 2004; 10: 96-100
98 Rustin GJ, Bradley C, Galbraith S et al. 5,6-dimethylxanthenone-4-acetic acid (DMXAA), a novel antivascular agent: phase I clinical and pharmacokinetic study. Br J Cancer 2003; 88: 1160 - 1167

99 Jameson MB, Thompson PI, Baguley BC et al. Clinical aspects of a phase I trial of 5,6-dimethylxanthenone-4-acetic acid (DMXAA), a novel antivascular agent. Br J Cancer 2003; 88: $1844-1850$

100 de Jonge MJ, van der Gaast A, Planting AS et al. Phase I and pharmacokinetic study of the dolastatin 10 analogue TZT-1027, given on days 1 and 8 of a 3 -week cycle in patients with advanced solid tumors. Clin Cancer Res 2005; 11: 3806-3813

101 Greystoke A, Blagden S, Thomas AL et al. A phase I study of intravenous TZT-1027 administered on day 1 and day 8 of a three-weekly cycle in combination with carboplatin given on day 1 alone in patients with advanced solid tumours. Ann Oncol 2006; 17: 1313-1319

102 Schoffski P, Thate B, Beutel $G$ et al. Phase I and pharmacokinetic study of TZT-1027, a novel synthetic dolastatin 10 derivative, administered as a 1-hour intravenous infusion every 3 weeks in patients with advanced refractory cancer. Ann Oncol 2004; 15: 671 - 679

103 Beerepoot LV, Radema SA, Witteveen EO et al. Phase I clinical evaluation of weekly administration of the novel vascular-targeting agent, ZD6126, in patients with solid tumors. J Clin Oncol 2006; 24: 1491 1498

104 Gadgeel SM, LoRusso PM, Wozniak AJ, Wheeler C. A dose-escalation study of the novel vascular-targeting agent, ZD6126, in patients with solid tumors. J Clin Oncol 2002; 21: a438 